\title{
Towards a Global Tree Assessment
}

\author{
Adrian Nemton, Sara Oldfield, Malin Rivers, Jennifer Mark \\ George Schatz, Natalia Tejedor Garavito, Elena Cantarello \\ Duncan Golicher, Luis Cayuela and Lera Miles
}

\begin{abstract}
Although trees have high economic, cultural and ecological value, increasing numbers of species are potentially at risk of extinction because of forest loss and degradation as a result of human activities, including overharvesting, fire and grazing. Emerging threats include climate change and its interaction with the spread of pests and diseases. The impact of such threats on the conservation status of trees is poorly understood. Here we highlight the need to conduct a comprehensive conservation assessment of the world's tree species, building on previous assessments undertaken for the IUCN Red List. We suggest that recent developments in plant systematics, online databases, remote sensing data and associated analytical tools offer an unprecedented opportunity to conduct such an assessment. We provide an overview of how a Global Tree Assessment could be achieved in practice, through participative, openaccess approaches to data sharing and evaluation.
\end{abstract}

Keywords Biodiversity, conservation, extinction risk, flora, forest, Red List, threat, tree

\section{Introduction}

7 rees are of high ecological, socio-economic and cultural 1 importance. As the principal component of forest ecosystems they support at least half of the Earth's terrestrial biodiversity (Millennium Ecosystem Assessment, 2005), providing habitat for $80 \%$ of amphibian, $75 \%$ of bird and $68 \%$ of mammal species (Vié et al., 2009). Tree species richness is a major driver of richness in other species groups (Novotny et al., 2006). Forest ecosystems play an important role in the Earth's biogeochemical processes, influencing hydrological, nutrient and carbon cycles as well as global

Adrian Newton (Corresponding author), Jennifer Mark, Natalia Tejedor Garavito, Elena Cantarello and Duncan Golicher Faculty of Science and Technology, Bournemouth University, Talbot Campus, Poole, Dorset BH12 5BB, UK. Email anewton@bournemouth.ac.uk

SARA OldField and Malin Rivers Botanic Gardens Conservation International, Richmond, Surrey, UK

George Schatz Missouri Botanical Garden, St. Louis, Missouri, USA

LuIs Cayuela Área de Biodiversidad y Conservación, Universidad Rey Juan Carlos, Móstoles (Madrid), Spain

Lera Miles United Nations Environment Programme World Conservation Monitoring Centre, Cambridge, UK

Received 6 November 2014. Revision requested 10 December 2014.

Accepted 22 January 2015. First published online 4 May 2015. climate (Millennium Ecosystem Assessment, 2005). Forests contain c. 50\% of terrestrial carbon stocks (Millennium Ecosystem Assessment, 2005; FAO, 2010) and are therefore important for mitigation of climate change. Trees provide a wide range of other benefits to people, including production of timber, fuelwood and fibre, maintenance of water yields and quality, flood protection, and prevention of soil erosion, as well as being of cultural and spiritual value (Millennium Ecosystem Assessment, 2005; UNEP, 2009). The ecosystem services provided by forests have an estimated annual value of USD 4.7 trillion, or $38 \%$ of the terrestrial total (Costanza et al., 1997). Circa 1.6 billion people depend to some degree on trees for their livelihoods (World Bank, 2004). The total contribution of forest industries to the global economy is c. USD 468 billion annually, with products valued at c. USD 122 billion harvested from forests each year (FAO, 2011).

The widespread loss and degradation of native forests is recognized as an environmental crisis. During 2000-2012 global forest area decreased by c. 2.3 million $\mathrm{km}^{2}$ (Hansen et al., 2013). During 2000-2010 the area of undisturbed primary forest declined by an estimated 4.2 million ha (0.4\%) per year, largely because of logging and other forms of human disturbance (FAO, 2010). The conversion and degradation of forest ecosystems are major causes of biodiversity loss (Millennium Ecosystem Assessment, 2005; UNEP, 2009; Vié et al., 2009). Their impacts on the decline and loss of tree species are largely unknown, however, because the status of tree species has not been comprehensively assessed.

We believe that a complete global assessment of the conservation status of tree species is an urgent priority. Recent analyses of extinction risk in selected animal groups, namely birds, mammals and amphibians, have demonstrated the value of such a comprehensive assessment approach. As a consequence of such efforts, it is now known that 14, 33 and $22 \%$ of bird, amphibian and mammal species, respectively, are either threatened with extinction or are extinct (Vié et al., 2009). The status of the world's tree species is less well understood. In 1998 an initial assessment involving c. 300 experts was conducted, which evaluated 14,000 taxa, of which 7,886 were found to be globally threatened (Oldfield et al., 1998). As the total number of extant tree species is uncertain, it is difficult to assess the coverage of this assessment with any precision. Based on the estimate of 60,000 tree species provided by Tudge (2005), some $84 \%$ of tree species currently await assessment. As of 


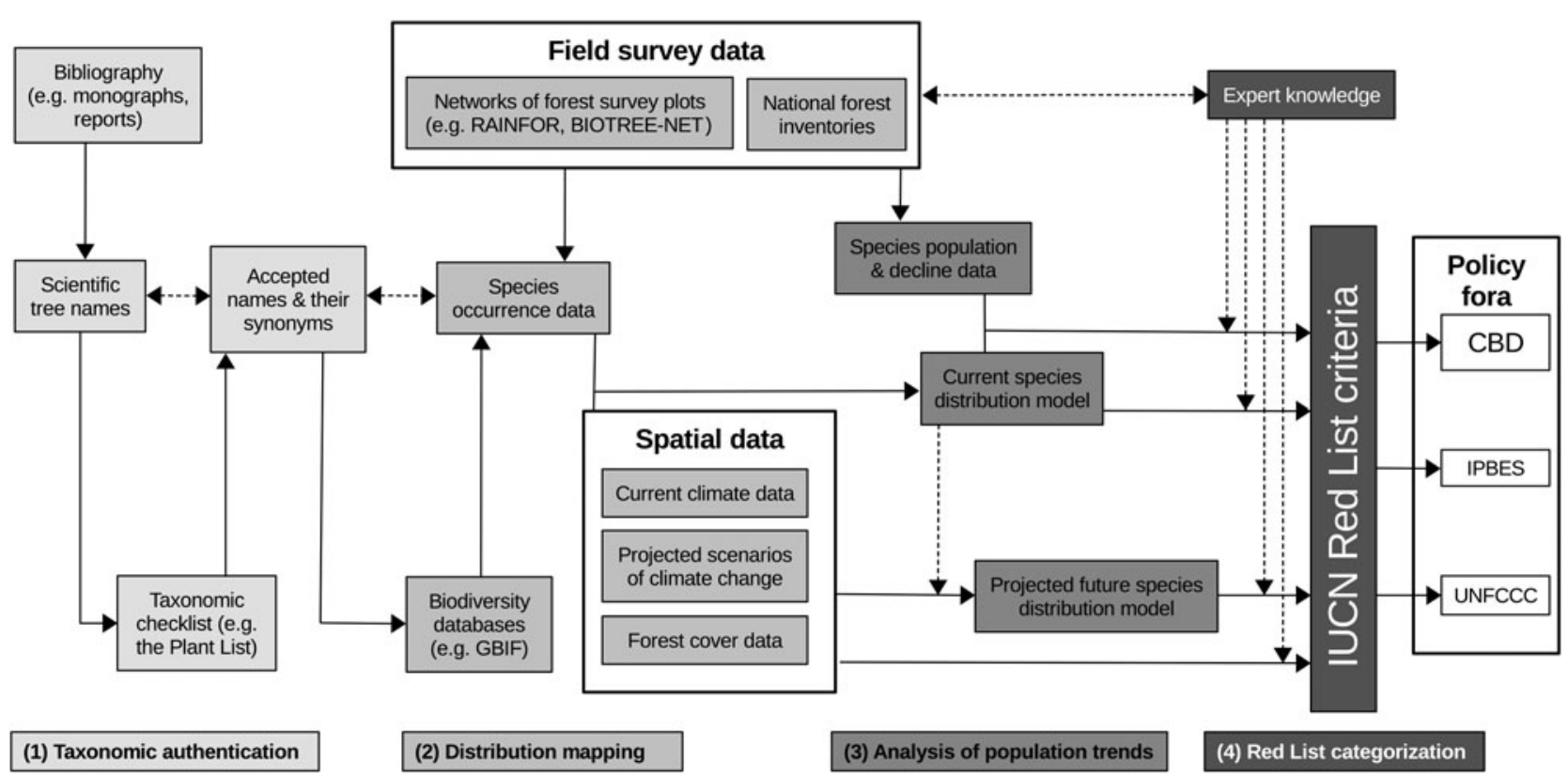

FIG. 1 Schematic illustration of a four-stage global tree assessment process, which could inform policy implementation at national and international scales. (1) Taxonomic authentication, involving identification of robust nomenclature for the taxa being assessed, through reference to bibliographies, monographs, checklists and taxonomic databases (e.g. The Plant List). (2) Distribution mapping, involving compilation of species distribution data from a range of sources, including databases (e.g. GBIF), national data centres, and networks of forest inventory and field survey plots. (3) Analysis of population trends, including compilation of abundance data from field observations, inventory data and other sources; and their integration with remote sensing data of trends in forest extent and condition, estimates of deforestation rates, etc. This integration could be supported by species distribution modelling approaches, which could be used to identify areas of potential distribution, allowing the impacts of climate change and other threats to be explored. (4) Application of Red List criteria and categories. Typically this would be undertaken by experts familiar with the taxa, supported by available maps, data and models. The engagement of such specialists throughout the process would be key to its success. Formally, responsibility for quality control during the process would lie with IUCN networks, such as the Global Tree Specialist Group of the IUCN Species Survival Commission.

November 2014 some 9,543 assessments of tree taxa were included in the IUCN Red List database (IUCN, 2014), representing slightly less than half of all plant species listed. Of these, 7,087 submissions were contributed by Oldfield et al. (1998), which now need to be updated. However, a number of additional assessments have been conducted since 1998, focusing on specific geographical regions or taxonomic groups, which have not yet been added to the IUCN Red List database (Newton \& Oldfield, 2008).

\section{Implementation of a Global Tree Assessment}

Implementation of a comprehensive Global Tree Assessment (Fig. 1) could follow the approaches adopted in recent assessments of vertebrate groups, which have successfully mobilized global data sets and expertise. The Global Amphibian Assessment, for example, involved inputs from $>500$ specialists, who evaluated the extinction risk of 5,743 species over a 3-year period (Stuart et al., 2004). Similarly, the Global Mammal Assessment was undertaken as a collaborative effort of $>1,700$ experts in 130 countries, with 5,487 species assessed over 5 years
(Schipper et al., 2008). Both of these assessments were undertaken as contributions to the IUCN Red List (IUCN, 2014), which is widely recognized to be the most authoritative global assessment of the conservation status of species (Mace et al., 2008). Red List assessments involve the application of quantitative criteria based on population size, distribution area and rate of decline, to assign species to different categories of relative extinction risk (IUCN, 2001). Information from the Red List has been widely used to inform conservation policies and legislation, as a tool for environmental monitoring and reporting, and to prioritize areas for conservation action (Lamoreux et al., 2003; Rodrigues et al., 2006; Mace et al., 2008); it has also been used at the global scale to monitor biodiversity loss (Butchart et al., 2010). Although the approach can be applied successfully to tree species (Newton \& Oldfield, 2008), most plant groups are grossly underrepresented in the Red List at present.

A Global Tree Assessment will represent a more substantial challenge than previous vertebrate assessments, given the much larger number of species involved. The Assessment will undoubtedly require the development of an extensive global collaborative partnership, involving the 
coordinated effort of many institutions and individuals. However, a number of recent developments have significantly increased the feasibility of undertaking such an assessment. Initiatives such as the Catalogue of Life (2014), The Plant List (2013) and the World Checklist of Selected Plant Families (WCSP, 2015) provide detailed catalogues of plant species, including digital links to regional and national floras and nomenclatural databases. Although these resources are not fully comprehensive and will continue to evolve in the light of ongoing taxonomic revisions, they will be useful in overcoming many problems of taxonomy and synonymy, which have hindered Red List assessments of plant species in the past (Nic Lughadha et al., 2005). These resources could be used to produce the first list of all tree species, as a first stage of the proposed assessment (Fig. 1).

A second key objective is the production of distribution maps of individual species, as part of the minimum supporting information required for an assessment to be published on the Red List. The Global Biodiversity Information Facility (GBIF, 2015) greatly facilitates production of species distribution maps, through an open access, globally distributed network of interoperable databases containing species location data. While it is recognized that these data are incomplete and spatially biased (Beck et al., 2014; Hjarding et al., 2014), they can be integrated with other spatial databases, such as Tropicos (Missouri Botanical Garden, 2015), and information derived from expert knowledge. Integration of multiple sources of evidence should strengthen the overall quality of assessments. Such integration could be supported by the recent development of online tools for species mapping, such as the Map of Life initiative (Jetz et al., 2011), GeoCAT (Bachman et al., 2011) and the IUCN Red List Threat Mapping Application (CEES, 2012). Other initiatives focus on the use of citizen science to support species mapping, for example iNaturalist and iSPOT. Such uses of Web 2.o technologies offer new approaches to collecting, mapping and sharing geocoded data (Hudson-Smith et al., 2009) and may facilitate a more participatory approach to Red List assessments. Location data can be explored using species distribution modelling approaches to produce distribution maps of large numbers of tree species, which can inform analyses of extinction risk (Feeley \& Silman, 2009; Golicher et al., 2011). In addition, high-resolution maps of changes in forest extent and condition over time, based on analysis of satellite remote sensing imagery, are increasingly becoming available (Wang et al., 2005; Hansen et al., 2008, 2010, 2013; Scholes et al., 2008). Developments in web technologies now make it possible for remote sensing data to be integrated with species distribution data and displayed as interactive maps accessible via the internet, which can further inform the analysis of range dynamics of tree species. Such integrative approaches can facilitate a more precise evaluation of changes in the distribution and population size of tree species (Buermann et al., 2008).
At the national scale, some countries with large numbers of tree species have made notable efforts to collect and review relevant data. For example, in 2007 the database compiled by the National Commission of Biodiversity of Mexico (CONABIO) contained 691,181 records of 28,085 species of vascular plants (Soberón et al., 2007), which are available for Red List assessments. Emerging networks of forest plot data, such as RAINFOR (Malhi et al., 2002) and BIOTREE (Cayuela et al., 2012), and the national forest inventories that have been established by many countries are additional potential sources of information. As an illustration of the value of plot networks, ter Steege et al. (2013) recently used data from 1,170 plots distributed across the Amazon basin to produce the first robust estimate of the total number of tree species in the region (c. 16,00o). Such data provide a valuable potential resource for conducting conservation assessments of tree species, which has been little used to date.

Although access to species distribution data and forest maps is improving, these alone are not sufficient for conducting Red List assessments, and expert knowledge is therefore likely to remain an important contributor to the process (Nic Lughadha et al., 2005). International networks of specialists have been established to support assessments of Mexican and Andean cloud forest trees (GonzálezEspinosa et al., 2011; Tejedor Garavito et al., 2015), providing a potential model for use in other regions. For many taxa, species distribution data are lacking, and therefore there is a need to strengthen field data collection efforts and local capacity, particularly in developing countries (Pereira \& Cooper, 2006; Simons, 2011). Tools are also available to assist conducting Red List assessments with uncertain data (Newton, 2010) but these have not been widely applied to date.

We propose to implement a Global Tree Assessment using a phased approach. A series of targeted assessments would be undertaken, focusing on specific plant families with a high representation of trees, such as Aquifoliaceae, Fabaceae, Fagaceae, Lauraceae, Meliaceae and Myrtaceae $(>20,000$ species in total). This would build on assessments of Betulaceae and Ebenaceae that are currently in progress, led by Botanic Gardens Conservation International and Missouri Botanical Garden, respectively. Themed assessments of important groups of species, such as fuelwood species, ecological keystone species and forest dominants, would also be undertaken. Work on assessing timber, medicinal and crop wild relative species has been initiated recently as part of the Plants for People initiative led by IUCN. Assessments would also prioritize species at most risk from climate change, such as montane and island trees (Hawkins et al., 2008), and from other threats such as overharvesting. The ultimate objective would be to assess the conservation status of all species, using this phased approach. 
It is recognized that implementation of these proposals would represent a significant advance over current assessment efforts. Since 1998 only 2,456 tree species have been added to the Red List database, although many thousands of additional assessments have been made that have not yet been incorporated into the database (Newton \& Oldfield, 2008; Botanic Gardens Conservation International, unpubl. data). However, to mark the 5oth anniversary of the Red List, IUCN recently initiated an accelerated process to increase the number of species assessed, with an aim of reaching 160,000 taxa by 2020 (IUCN, 2015). This requires a significant increase in the number of experts trained to carry out Red List assessments, as well as provision of sufficient resources, for which targeted fundraising is in progress (IUCN, 2015). A Global Tree Assessment could make a substantial contribution to this initiative, if sufficient financial resources were available.

Few data are available on the cost of undertaking Red List assessments. Martinelli \& Moraes (2013) suggested that such costs vary widely (USD 26-440 per taxon) depending on the species involved. IUCN (2015) estimates a cost of USD 250 per taxon, which seems realistic for tree species, based on recent experience (Newton \& Oldfield, 2008). However, improvements in data availability, digital applications and associated tools, and adoption of the participatory assessment approach outlined here should help make the process more cost efficient. This is illustrated by the example of the South African flora, which was assessed at a cost of USD $<30$ per taxon. This was achieved by establishing a centralized team of ecologists to develop Red Lists, collaborating with a wide range of botanical experts, streamlining the assessment process via automation, and establishing an appropriate data management system (Raimondo et al., 2013). This approach facilitated the assessment of 20,456 vascular plants within 5 years, suggesting that substantial progress towards a Global Tree Assessment could be achieved by 2020 using similar methods if sufficient resources were made available.

\section{Outcomes}

Key outcomes of the assessment would include improved targeting of conservation resources specifically for tree conservation, improved design of forest conservation, restoration and management programmes, and strengthened capacity for sustainable forest management and land planning. Re-evaluation of tree species will facilitate estimation of trends in extinction risk, for example through calculation of the Red List Index (Butchart et al., 2010; Kew, 2010), providing timely and useful policy-relevant information on biodiversity trends, and contributing to the 'Barometer of Life' proposed by Stuart et al. (2010).

A global Red List assessment of tree species would support a variety of policy initiatives, including the Convention on Biological Diversity (CBD) and the UN Framework
Convention on Climate Change (UNFCCC). The Strategic Plan for Biodiversity agreed at the Tenth Meeting of the Conference of the Parties to the CBD (COP10) in Nagoya, Japan, identified trends in distribution and extinction risk of species as key operational indicators. Target 2 of the Global Strategy for Plant Conservation, a cross-cutting initiative of the CBD, refers to 'an assessment of the conservation status of all known plant species, as far as possible, to guide conservation action' by 2020. A Global Tree Assessment would be an important contributor to this target. In addition, it would support implementation of the UN Framework Convention on Climate Change, which aims to tackle greenhouse gas emissions from deforestation and forest degradation through the REDD+ (Reducing Emissions from Deforestation and Forest Degradation) programme. Recognizing the potential for social and environmental risks and benefits from this programme (Miles \& Kapos, 2008; Ghazoul et al., 2010), the UN has agreed a set of broad safeguards, specifically focusing on the conservation of natural forests and biodiversity. Improved information on the conservation status of tree species would help to focus REDD+ activities and enhance the conservation impacts of these activities.

Red List assessments would also help prioritize tree species for conservation action. The urgency of conducting a Global Tree Assessment is highlighted by current concerns regarding large-scale die-back of trees, in both temperate and tropical forests, resulting from emerging threats such as the rapid spread of pests, disease and drought, and their interactions with global climate change (Breshears et al., 2005; Huntingford et al., 2008; Kurz et al., 2008; Raffa et al., 2008; Allen, 2009; van Mantgem et al., 2009). Concerns have also been expressed regarding 'peak timber' in the tropics, reflecting widespread overexploitation of timber (Shearman et al., 2012), and a global decline in large, old trees, which may threaten ecosystem integrity (Lindenmayer et al., 2012). Such factors, together with the ongoing loss and degradation of forest, can potentially threaten large numbers of tree species. As illustration, of 762 species evaluated in a recent assessment of Mexican cloud forest tree species, $>60 \%$ were found to be threatened with extinction (González-Espinosa et al., 2011). This highlights the urgent need to identify threatened tree species worldwide and take immediate steps to prevent their extinction.

\section{Conclusions}

We believe that the timing is right for launching a Global Tree Assessment. Achievement of this ambitious goal will require the development of an unprecedented global network of botanical specialists, conservation practitioners, naturalists and plant ecologists with interests in tree conservation. We believe that recent developments in computing 
and web technologies will greatly facilitate the building of such an alliance, by providing tools for accessing and sharing information about the status of individual species. In this way, undertaking tree conservation assessments can become a more open, transparent and participatory process, in which contributors from anywhere in the world can become involved. Nevertheless, for this vision to be achieved a high level of commitment will be required from the global conservation community, which will need to be sustained over a number of years. There is also a need for the provision of sufficient financial support to ensure that the assessment can be conducted successfully. We invite individuals and organizations who are concerned about the status of tree species to contribute to this process, to help conserve this vitally important element of global biodiversity.

\section{Acknowledgements}

We thank Steven Bachman, Mario Gonzalez Espinosa, Valerie Kapos, Nicholas King, Gustavo Martinelli, Jane Smart and Simon Stuart for their comments on a draft version of the text.

\section{References}

Allen, C.D. (2009) Climate-induced forest dieback: an escalating global phenomenon? Unasylva, 6o, 43-49.

Bachman, S., Moat, J., Hill, A.W., de la Torre, J. \& Scott, B. (2011) Supporting Red List threat assessments with GeoCAT: geospatial conservation assessment tool. ZooKeys, 150, 117-126.

Beck, J., Böller, M., Erhardt, A. \& Schwanghart, W. (2014) Spatial bias in the GBIF database and its effect on modeling species' geographic distributions. Ecological Informatics, 19, 10-15.

Breshears, D.D., Cobb, N.S., Rich, P.M., Price, K.P., Allen, C.D., B ALICE, R.G. et al. (2005) Regional vegetation die-off in response to global-change-type drought. Proceedings of the National Academy of Sciences of the United States of America, 102, 15144-15148.

Buermann, W., SaAtchi, S., Smith, T.B., Zutta, B.R., Chaves, J.A., Milá, B. \& Graham, C.H. (2008) Predicting species distributions across the Amazonian and Andean regions using remote sensing data. Journal of Biogeography, 35, 1160-1176.

Butchart, S.H.M., Walpole, M., Collen, B., van Strien, A., Scharlemann, J.P.W., Almond, R.E.A. et al. (2010) Global biodiversity: indicators of recent declines. Science, 328, 1164-1168.

Catalogue of Life (2014) Http://www.catalogueoflife.org/ [accessed 30 January 2015].

Cayuela, L., Gálvez-Bravo, L., Pérez, R.P., de Albuquerque, F.S., Golicher, D.J., Zahawi, R.A. et al. (2012) The Tree Biodiversity Network (BIOTREE-NET): prospects for biodiversity research and conservation in the Neotropics. Biodiversity and Ecology, 4, 211-224.

CEES (Computational Ecology and Environmental Science Group) (2012) Http://research.microsoft.com/en-us/projects/ threatmapping/ [accessed 30 January 2015].

Costanza, R., D’Arge, R., de Groot, R., Farber, S., Grasso, M., Hannon, B. et al. (1997) The value of the world's ecosystem services and natural capital. Nature, 387, 253-260.
FAO (Food and Agriculture Organization of the United Nations) (2010) Global Forest Resources Assessment, 2010-Main Report. FAO Forestry Paper 163. FAO, Rome, Italy.

FAO (2011) State of the World's Forests 2011. FAO, Rome, Italy.

Feeley, K.J. \& Silman, M.R. (2009) Extinction risks of Amazonian plant species. Proceedings of the National Academy of Sciences of the United States of America, 106, 12382-12387.

GBIF (Global Biodiversity Information Facility) (2015) Http://www.gbif.org [accessed 30 January 2015].

Ghazoul, J., Butler, R.A., Mateo-Vega, J. \& Кoн, L.P. (2010) REDD: a reckoning of environment and development implications. Trends in Ecology \& Evolution, 25, 396-402.

Golicher, D.J., Cayuela, L. \& Newton, A.C. (2011) Effects of climate change on the potential species richness of Mesoamerican forests. Biotropica, 44, 284-293.

González-Espinosa, M., Meave, J.A., Lorea-Hernández, F.G., Ibarra-Manríquez, G. \& Newton, A.C. (eds) (2011) The Red List of Mexican Cloud Forest Trees. Fauna \& Flora International, Cambridge, UK.

Hansen, M.C., Potapov, P.V., Moore, R., Hancher, M., Turubanova, S.A., Tyukavina, A. et al. (2013) High-resolution global maps of 21st-century forest cover change. Science, 342, $850-853$.

Hansen, M.C., Stehman, S.V. \& Potapov, P.V. (2010) Quantification of global gross forest cover loss. Proceedings of the National Academy of Sciences of the United States of America, 107, $8650-8655$.

Hansen, M.C., Stehman, S.V., Potapov, P.V., Loveland, T.R., Townshend, J.R.G., DeFries, R.S. et al. (2008) Humid tropical forest clearing from 2000 to 2005 quantified by using multitemporal and multiresolution remotely sensed data. Proceedings of the National Academy of Sciences of the United States of America, 105, 9439-9444.

Haw kins, B., Sharrock, S. \& Havens, K. (2008) Plants and Climate Change: Which Future? Botanic Gardens Conservation International, Richmond, UK.

Hjarding, A., Tolley, K.A. \& Burgess, N.D. (2014) Red List assessments of East African chameleons: a case study of why we need experts. Oryx, http://dx.doi.org/10.1017/So030605313001427 [accessed 30 January 2015].

Hudson-Smith, A., B Atty, M., Crooks, A. \& Milton, R. (2009) Mapping for the masses. Accessing Web 2.0 through crowdsourcing. Social Science Computer Review, 27, 524-538.

Huntingford, C., Fisher, R.A., Mercado, L., Booth, B.B.B., Sitch, S., Harris, P.P. et al. (2008) Towards quantifying uncertainty in predictions of Amazon 'die-back'. Philosophical Transactions of the Royal Society of London B, 363 , 1857-1864.

INAturalist (undated) Http://www.inaturalist.org/ [accessed 30 January 2015].

IS рот (undated) iSpot. The Open University, Milton Keynes, UK. Http://www.ispotnature.org/ [accessed 30 January 2015].

IUCN (2001) 2001 Categories and Criteria (version 3.1). IUCN, Gland, Switzerland.

IUCN (2014) IUCN Red List of Threatened Species v. 2014.3. Http:// www.iucnredlist.org [accessed 30 January 2015].

IUCN (2015) A campaign to support The IUCN Red List. Http://50. iucnredlist.org/ [accessed 15 January 2015].

Jetz, W., McPherson, J.M. \& Guralnick, R.P. (2011) Integrating biodiversity distribution knowledge: toward a global map of life. Trends in Ecology \& Evolution, 27, 151-159.

KEw (2010) Plants Under Pressure: A Global Assessment. The first report of the IUCN Sampled Red List Index for Plants. Royal Botanic Gardens, Kew, UK. 
Kurz, W.A., Stinson, G., Rampley, G.J., Dymond, C.C. \& Neilson, E.T. (2008) Risk of natural disturbances makes future contribution of Canada's forests to the global carbon cycle highly uncertain. Proceedings of the National Academy of Sciences of the United States of America, 105, 1551-1555.

Lamoreux, J., Akçakaya, R., Bennun, L., Collar, N.J., Boitani, L., Brackett, D. et al. (2003) Value of the IUCN Red List. Trends in Ecology \& Evolution, 18, 214-215.

Lindenmayer, D.B., Laurance, W.F. \& Franklin, J.F. (2012) Global decline in large old trees. Science, 338, 1305-1306.

Mace, G.M., Collar, N.J., Gaston, K.J., Hilton-Taylor, C., AKÇakaya, H.R., Leader-Williams, N. et al. (2008) Quantification of extinction risk: IUCN's system for classifying threatened species. Conservation Biology, 22, 1424-1442.

Malhi, Y., Phillips, O.L., Lloyd, J., Baker, T.R., Wright, J., Almeida, S. et al. (2002) An international network to monitor the structure, composition and dynamics of Amazonian forests (RAINFOR). Journal of Vegetation Science, 13, 439-450.

Martinelli, G. \& Moraes, M.A. (2013) Livro vermelho da flora do Brasil. Instituto de Pesquisas, Jardim Botânico do Rio de Janeiro, Rio de Janeiro, Brazil.

Miles, L. \& Kapos, V. (2008) Reducing greenhouse gas emissions from deforestation and forest degradation: global land-use implications. Science, 320, 1454-1455.

Millennium Ecosystem Assessment (2005) Ecosystems and Human Well-being: Current State and Trends. Island Press, Washington, DC, USA.

Missouri Botanical Garden (2015) Tropicos. Http://www.tropicos. org/ [accessed 30 January 2015].

Newton, A.C. (2010) Use of a Bayesian network for Red Listing under uncertainty. Environmental Modelling \& Software, 25, 15-23.

Newton, A.C. \& Oldfield, S. (2008) Red Listing the world's tree species: a review of recent progress. Endangered Species Research, 6, 137-147.

Nic Lughadha, E., Baillie, J., Barthlott, W., Brummitt, N.A., Cheek, M.R., Farjon, A. et al. (2005) Measuring the fate of plant diversity: towards a foundation for future monitoring and opportunities for urgent action. Philosophical Transactions of the Royal Society of London B, 360, 359-372.

Novotny, V., Drozd, P., Miller, S.E., Kulfan, M., Janda, M., BASSET, Y. \& W EIBLEN, G.D. (2006) Why are there so many species of herbivorous insects in tropical rainforests? Science, 313, 1115-1118.

Oldfield, S., Lusty, C. \& MacKinven, A. (1998) The World List of Threatened Trees. World Conservation Press, UNEP-WCMC, Cambridge, UK.

Pereira, H.M. \& Cooper, H.D. (2006) Towards the global monitoring of biodiversity change. Trends in Ecology \& Evolution, 21, 123-129.

Raffa, K.F., Aukema, B.H., Bentz, B.J., Carroll, A.L., Hicke, J.A., Turner, M.G. \& Romme, W.H. (2008) Cross-scale drivers of natural disturbances prone to anthropogenic amplification: the dynamics of bark beetle eruptions. BioScience, 58, 501-517.

Raimondo, D.C., von Staden, L. \& Donaldson, J.S. (2013) Lessons from the conservation assessment of the South African megaflora. Annals of the Missouri Botanical Garden, 99, 221-230.

Rodrigues, A.S.L., Pilgrim, J.D., Lamoreux, J.F., Hoffmann, M. \& BRooks, T.M. (2006) The value of the IUCN Red List for conservation. Trends in Ecology \& Evolution, 21, 71-76.

Schipper, J., Chanson, J.S., Chiozza, F., Cox, N.A., Hoffmann, M., Katariya, V. et al. (2008) The status of the world's land and marine mammals: diversity, threat, and knowledge. Science, 322, $225-230$.
Scholes, R.J., Mace, G.M., Turner, W., Geller, G.N., Jürgens, N., LARigauderie, A. et al. (2008) Toward a global biodiversity observing system. Science, 321, 1044-1045.

Shearman, P., Bryan, J. \& Laurance, W.F. (2012) Are we approaching 'peak timber' in the tropics? Biological Conservation, $151,17-21$.

Simons, C. (2011) Uncertain future for tropical ecology. Science, 332, 298-299.

Soberón, J., Jiménez, R., Golubov, J. \& Koleff, P. (2007) Assessing completeness of biodiversity databases at different spatial scales. Ecography, 30, 152-160.

Stuart, S.N., Chanson, J.S., Cox, N.A., Young, B.E., Rodrigues, A.S.L., Fischman, D.L. \& Waller, R.W. (2004) Status and trends of amphibian declines and extinctions worldwide. Science, 306, 1783-1786.

Stuart, S.N., Wilson, E.O., McNeely, J.A., Mittermeier, R.A. \& Rodríguez, J.P. (2010) The barometer of life. Science, $328,117$.

Tejedor Garavito, N., Álvarez, E., Arango Caro, S., Araujo Murakami, A., Baldeón, S., Beltran, H. et al. (2015) The Red List of Montane Tree Species of the Tropical Andes: Trees at the Top of the World. Botanic Gardens Conservation International, Richmond, UK.

ter Steege, H., Pitman, N.C.A., Sabatier, D., Baraloto, C., Salomão, R.P., Guevara, J.E. et al. (2013) Hyperdominance in the Amazonian tree flora. Science, 342, 1243092.

The Plant List (2013) Http://www.theplantlist.org/ [accessed 30 January 2015].

Tudge, C. (2005) The Secret Life of Trees. Penguin Books, London, UK.

UNEP (2009) Vital Forest Graphics. GRID-Arendal, Arendal, Norway.

van Mantgem, P.J., Stephenson, N.L., Byrne, J.C., Daniels, L.D., Franklin, J.F., Fulé, P.Z. et al. (2009) Widespread increase of tree mortality rates in the western United States. Science, 323, 521-524.

Vié, J.-C., Hilton-Taylor, C. \& Stuart, S.N. (eds) (2009) Wildlife in a Changing World: An Analysis of the 2008 IUCN Red List of Threatened Species. IUCN, Gland, Switzerland.

WanG, C., QI, J.G. \& Cochrane, M. (2005) Assessment of tropical forest degradation with canopy fractional cover from Landsat ETM+ and IKONOS imagery. Earth Interactions, 9, 1-18.

WCSP (2015) World Checklist of Selected Plant Families. Facilitated by the Royal Botanic Gardens, Kew, UK. Http://apps.kew.org/wcsp/ [accessed 30 January 2015].

World Bank (2004) Sustaining Forests: A Development Strategy. World Bank, Washington, DC, USA.

\section{Biographical sketches}

Adrian Newton, Jennifer Mark, Natalia Tejedor Garavito, Elena Cantarello, Duncan Golicher and Luis CAYUELA are forest conservation ecologists with particular interests in tree species. SARA OLDFIELD and ADRIAN NEWTON are co-chairs of the IUCN SSC Global Trees Specialist Group, responsible for Red List assessments of the world's tree species, and MALIN RIVERS is Secretary of the group. George Schatz has research interests in plant systematics and conservation assessments, with a particular focus on East Africa and Madagascar. Lera Miles is a specialist on global forest policy. 